\title{
Differential effects of self-esteem and interpersonal competence on humor styles
}

\author{
Bernadette McCosker \\ Carmen C Moran \\ School of Psychology, Charles Sturt \\ University, Wagga Wagga, NSW, \\ Australia
}

This article was published in the following Dove Press journal:

Psychology Research and Behavior Management

25 October 2012

Number of times this article has been viewed

Background: In contrast with an early implicit "facilitative hypothesis" of humor, a revised specificity hypothesis predicts that the benefits of humor depend on the specific style of humor used. Information on predictors of these humor styles in turn enhances the ability to predict the effect on well-being.

Methods: We examined the relationships between interpersonal competence, self-esteem, and different styles of humor, while also examining the contributions of age and gender. Participants $(\mathrm{n}=201)$ aged $18-63$ years completed the Rosenberg Self-Esteem Inventory, the Interpersonal Competence Questionnaire, and the Humor Styles Questionnaire, and gave demographic information.

Results: High self-esteem was associated with higher use of affiliative, aggressive, and selfenhancing humor styles, but lower use of self-defeating humor. High interpersonal competence predicted greater use of affiliative humor, whereas low interpersonal competence predicted greater use of aggressive humor. Further analyses showed that initiation competence predicted affiliative humor (positively) but both initiation competence (positively) and conflict management competence (negatively) predicted aggressive humor.

Conclusion: The findings that both self-esteem and initiation competence contribute to use of aggressive humor add to knowledge of who is likely to use this potentially harmful humor style. We conclude that a readiness to initiate humorous interactions is not on its own a general and positive attribute contributing to "good" humor.

Keywords: self-esteem, interpersonal competence, humor styles, differential effects

\section{Background}

Researchers have often adopted an implicit "facilitative hypothesis" of humor to demonstrate positive but general effects of humor. ${ }^{1}$ To some extent, the hypothesis was initially supported because several studies reported individuals with a greater sense of humor (variously measured) have higher self-esteem, lower levels of depression, anxiety and perceived stress, and a more positive self-concept, better overall mental and physical health, enhanced ability to cope with stress, and better relationships with other people..$^{2-4}$ There was not necessarily a reduction in stressors, because using humor to cope, including laughing under moderately stressful conditions, while related to lower levels of depression and better well-being, does not predict fewer stressors. ${ }^{5-7}$ Those with a greater sense of humor appear to derive greater pleasure and satisfaction from various social experiences and life events, and are more mentally tough when stressed..$^{3,4,8-10}$ 
With such results to support it, the older facilitative view of humor continues to inform views of humor, with such claims as "humor can help an individual to climb the ladder of social hierarchy - to be accepted, win affection, and to gain status. It can also help him to avoid sanctions." "I1 In contrast with this positive view, other articles suggest humor can be harmful. ${ }^{12,13}$ While the idea that humor can be harmful is not new, ${ }^{14,15}$ contemporary psychological research has been largely focused on treating humor as a healthy and positive characteristic. Nevertheless, a revised specificity hypothesis predicts that the benefits of humor depend on the style of humor used and this has resulted in the search for the best means of predicting humor style.

Humor is a complex multidimensional construct, involving a number of emotional, cognitive, and behavioral components, with social and physiological manifestations and reactions. ${ }^{16}$ In that sense, humor resembles many other emotions or behaviors. "Humor" is used to refer to several factors, for example, a cognitive process such as the perception and resolution of an incongruity, or the emotional reaction of pleasure or the stimulus that makes one laugh, such as a joke, or the response, such as laughter. ${ }^{17}$ Many psychological studies consider humor as a personal characteristic or style, often labeled as "sense of humor". Some questionnaires treat humor as a personality variable, some measure attitudes, some measure ability to produce humor, and others measure some combination of liking and producing humor. ${ }^{18}$ Different aspects of humor can thus alter the observed relationship between humor and well-being. Taking just a few examples, Edwards and Martin ${ }^{19}$ reported that the ability to produce humor (add witty captions to cartoons) did not predict who would score higher on well-being measures, whereas sense of humor scores did. On the other hand, sense of humor did not predict relationship quality, but ability to produce humor did, at least for women. ${ }^{20}$ A personal liking for humor, a subscale of Thorson and Powell's Multidimensional Sense of Humor Scale, has been negatively associated with wellbeing. ${ }^{21}$ Laughter, while not the same as humor, may also be associated with positive or negative messages in social situations. $^{22}$

As a result of the above research and more, contemporary multidimensional models of "sense of humor" now acknowledge both the positive and negative elements and thus go beyond a facilitative hypothesis. ${ }^{12,23}$ In these models, humor is categorized as a maladaptive style (eg, self-defeating, aggressive) or an adaptive style (eg, coping, affiliative, self-enhancing, and skilled). This categorization leads to a specificity hypothesis of humor, where the impact of humor is predicted to be specific to the type of humor used., ${ }^{1,23}$ Adaptive positive humor styles are labeled as such because they have been associated with higher self-esteem, positive affect, and better ability to control anxiety and to initiate social interactions. Maladaptive negative styles of humor that are self-focused have been associated with lower well-being, higher perceptions of stress, and low self-esteem. ${ }^{1,24-26}$ Other directed negative humor styles, especially aggressive humor, are less consistently related to well-being measures.

One scale derived from the specificity hypothesis is the Humor Styles Questionnaire (HSQ), which describes two positive humor styles (affiliative and self-enhancing humor) and two negative humor styles (aggressive and self-defeating humor). ${ }^{23}$ The items reflect ways in which humor is typically expressed in social situations ${ }^{27}$ and ways people use humor to cope and communicate. ${ }^{28}$ Using the HSQ, Dozois et al reported that selfenhancing humor was positively associated with variables such as high self-esteem and cheerfulness, and negatively associated with depression and anxiety, and that affiliative humor was associated with variables relating to relationships, such as intimacy, social support, and interpersonal competence. ${ }^{28}$ In the same study, aggressive humor was negatively associated with interpersonal competence, and self-defeating humor was negatively associated with self-esteem and positively with anxiety and depression. ${ }^{28}$ The self-directed humor styles, ie, self-enhancing humor and self-defeating humor, were concluded to be "important for emotional well-being" in contrast with the other-directed humor styles, ie, affiliative humor and aggressive humor, which were considered to predict the quality of interpersonal relationships. ${ }^{28}$

Social relationship variables, such as marital satisfaction, perceived social support, and quality of social interactions, have also been related to the HSQ or to similar humor indices. For example, loneliness is predicted by both low interpersonal competence and a low use of positive humor. ${ }^{29}$ In such cases, it is humor use (or lack of it) which predicts the nature of the association. Just appreciating a partner's humor or liking the same jokes, for example, does not appear to be sufficient to predict relationship quality over time, although it may enhance initial attraction. ${ }^{20}$

Based on the relationship between positive humor styles, well-being, and good interpersonal relationships, it would be expected that individuals who score high on "positive" humor would be those who have the social skills to use humor in ways that enhance their own and others' wellbeing, and conversely those who do not have those skills will be less likely to use those humor styles. There is some evidence to support this. Bell et al reported that interpersonal 
competence, especially assertiveness, was more important than self-esteem in predicting humor use in young and older subjects, and the effect was strongest in males. ${ }^{30}$ Similarly, Graham et al reported correlations between interpersonal competence and positive (but not negative) uses of humor measured on their Uses of Humor Index, and directly claimed that the ability to use humor "is a measure of one's' interpersonal competence". ${ }^{31}$ In their study, they did not distinguish between self-directed or other-directed humor styles, although they did classify "self-disclosure" humor. In contrast, Yip and Martin ${ }^{27}$ reported interpersonal competence was correlated with both positive and negative uses of humor, and the relationships occurred on different subscales of interpersonal competence. There is less information on characteristics of those using aggressive humor, or at least null outcomes in statistical tests. Given that self-esteem has been related to humor styles ${ }^{1,25,32,33}$ and that self-esteem is correlated with interpersonal competence, ${ }^{1,34,35}$ it is theorized that interpersonal competence will account for the relationship between self-esteem and humor, but in different directions for positive and negative styles of humor.

\section{Materials and methods Participants and procedures}

A total of 201 individuals (145 females, 56 males) participated in this study, and were sampled on the basis of availability. They responded to direct requests via snowballing across adult social networks and to an online request at an Australian university (which includes a large proportion of distance education students). There was no screening of subjects, other than a requirement to be at or above the age of 18 years. The age range of participants in this study was $18-63$ (mean $29.86 \pm 0.86$ ) years, and the participants were predominantly Caucasian in origin. The full survey, including demographic data and questionnaires, was completed online using the Survey Monkey tool. All participants completed the survey in the same order, with demographic data completed first then the questionnaires in the order presented below. Because participants were invited to participate anonymously, only basic demographic information on the sample characteristics is available. Ethics approval was obtained through the Charles Sturt University human research ethics process.

\section{Materials}

\section{Humor Styles Questionnaire}

The HSQ presents 32 self-rated items on a seven-point Likert scale across four styles of humor use, ie, affiliative, self-enhancing, aggressive, and self-defeating humor. Examples of the humor style items are: "I laugh and joke a lot with friends" (affiliative), "If I am feeling depressed, I can usually cheer myself up with humor" (self-enhancing), "If someone makes a mistake, I will often tease them about it" (aggressive), and "I will often get carried away in putting myself down if it makes my family or friends laugh" (selfdefeating). Good reliability for each of the subscales has been demonstrated. ${ }^{23,36}$

\section{Rosenberg Self-Esteem Inventory}

The Rosenberg Self-Esteem Inventory (RSEI) ${ }^{37}$ is a 10 -item self-report measure of an individual's level of global self-esteem. ${ }^{38}$ Example items include "On the whole, I am satisfied with myself" and "At times I think I am no good at all" (reverse scored). All the items are answered using a four-point Likert scale ranging from (1) "strongly disagree" to (4) "strongly agree". Internal consistency and test-retest reliabilities for the Rosenberg Self-Esteem Inventory are good. $^{38}$

\section{Interpersonal Competence Questionnaire}

The Interpersonal Competence Questionnaire (ICQ) ${ }^{35}$ is a 40-item self-report measure of self-competence in which participants are asked to rate their ability to handle a variety of interpersonal tasks in five different interpersonal competence domains, ie, initiating relationships, personal disclosure, negative assertion, emotional support, and conflict management. Each interpersonal domain is assessed on items that tap both new and close relationships. Participants rate each item on a five-point Likert scale. The scale has good reliability. ${ }^{35}$

\section{Analyses}

Although gender differences were not a focus of this research, they were examined because differences are regularly reported for aggressive styles of humor. Age was also considered, because while differences across age are less consistently noted, this may be a result of the restricted age range in several humor studies. Analyses of variance were performed on mean scores of the study variables to test differences across both gender and age. Hierarchical multiple regression was used with each of the humor subscales serving as dependent variables. Self-esteem was entered first as the main predictor, after controlling for the influence of age and gender. Once the effect of self-esteem was accounted for, interpersonal competence was examined. Preliminary analyses ensured no violation of the assumptions of 
normality, linearity, multicollinearity, and homoscedasticity. All regression calculations were conducted using the PASW version 17 package (SPSS Inc, Chicago, IL)

\section{Results}

\section{Humor styles, self-esteem,} and interpersonal competence by gender

Table 1 presents the means and standard deviations for the HSQ, RSEI, and ICQ separately for male and female participants. As expected, males scored significantly higher on aggressive humor. None of the other comparisons approached significance.

\section{Humor styles, self-esteem, and interpersonal competence by age}

Skewness toward younger participants $(1.03, \mathrm{z}=0.17)$ in the age data was assessed as not in violation of the normality assumption. ${ }^{39}$ Further, there was little difference between the $5 \%$ trimmed mean for age of 28.89 years compared with the original mean of 29.86 years, which suggests little influence of extreme scores. To examine age differences on the four HSQ scales, the RSEI, and the ICQ, the Visual Binning method in PASW were used to create three age groups (ie, categorical values). In this method, cutoffs were selected at points in the age distribution which resulted in groups with reasonably sized numbers of participants while also keeping meaningful intervals. Our three age groups may be seen to represent adolescents/early adults, young adults, and older adults. Table 2 presents the means and standard deviations for the three age groups, and subgroup numbers.

The analysis of variance for the means for the three groups (categorized by age) reveals significant differences in three of the humor scales, namely affiliative, aggressive,

Table I Results of analysis of variance for gender differences in mean humor style, self-esteem, and interpersonal competency dimensions

\begin{tabular}{llll}
\hline Scale & \multicolumn{2}{l}{ Means (SD) } & $\boldsymbol{F}$ \\
\cline { 2 - 3 } & Males & Females & \\
\hline Humor Styles Questionnaire & & & \\
$\quad$ Affiliative & $47.48(6.50)$ & $45.8 I(7.26)$ & 2.26 \\
$\quad$ Self-enhancing & $37.02(6.90)$ & $36.79(8.45)$ & 0.03 \\
$\quad$ Aggressive & $33.29(6.91)$ & $28.01(8.09)$ & $18.55 * * *$ \\
$\quad$ Self-defeating & $29.20(7.98)$ & $28.70(9.52)$ & 0.12 \\
Rosenberg Self-Esteem Inventory & $31.91(5.89)$ & $30.4 I(5.02)$ & 3.3 \\
Interpersonal competence & $13.33(2.35)$ & $13.83(1.86)$ & 2.5 \\
questionnaire & & & \\
\hline
\end{tabular}

Note: $* * * P<0.0001$.

Abbreviation: SD, standard deviation.
Table 2 Results of analysis of variance for age differences in mean humor style, self-esteem, and interpersonal competency dimensions

\begin{tabular}{|c|c|c|c|c|}
\hline \multirow[t]{4}{*}{ Scale } & \multicolumn{3}{|l|}{ Means (SD) } & \multirow[t]{4}{*}{$F$} \\
\hline & \multicolumn{3}{|l|}{ Age, years } & \\
\hline & $|8-2|$ & $22-33$ & $34-63$ & \\
\hline & $(n=85)$ & $(n=49)$ & $(n=67)$ & \\
\hline \multicolumn{5}{|c|}{ Humor Styles Questionnaire } \\
\hline Affiliative & $47.25(6.28)$ & $46.98(7.34)$ & $44.54(7.60)$ & $3.13 *$ \\
\hline Self-enhancing & $36.13(6.93)$ & $36.33(8.93)$ & $38.16(8.58)$ & 1.35 \\
\hline Aggressive & $31.71(7.65)$ & $28.84(8.05)$ & $27.13(8.10)$ & $6.5 * * *$ \\
\hline Self-defeating & $30.88(9.05)$ & $28.55(9.6 \mathrm{I})$ & $26.45(8.26)$ & $4.7^{* *}$ \\
\hline Rosenberg & $30.08(5.57)$ & $30.61(5.27)$ & $31.93(4.87)$ & 2.34 \\
\hline \multicolumn{5}{|c|}{ Self-Esteem Inventory } \\
\hline Interpersonal & $13.77(1.96)$ & |3.8| (2.09) & $13.50(2.05)$ & 0.46 \\
\hline \multicolumn{5}{|l|}{ Competence } \\
\hline Questionnaire & & & & \\
\hline
\end{tabular}

and self-defeating humor. On all significant measures, post hoc comparisons using Tukey HSD (honestly significant difference) tests indicated differences lay between the age group of 18-21 years and the age group of 34-63 years. There were no significant differences across age for the RSEI and ICQ.

\section{Hierarchical multiple regression}

Given the literature has linked self-esteem and interpersonal competence to humor styles, albeit to varying degrees, the next step in the analysis was to examine the unique contributions of self-esteem and interpersonal competence to humor styles. Four hierarchical multiple regressions were tested with each of the humor subscales as dependent (criterion) variables, and self-esteem and interpersonal competence as predictors, entered after age and gender. The results are summarized in Tables 3-6.

The results indicate that, consistent with the analysis of variance results, gender contributed to aggressive humor but not the other styles, and age to affiliative, aggressive, and self-defeating humor. In step two, self-esteem contributed to the three humor styles labeled affiliative, self-enhancing, and self-defeating but, at this stage, did not contribute to aggressive humor. In the third and final step, ICQ scores added an additional and unique contribution to affiliative and aggressive humor but not the other styles. For aggressive humor, once ICQ scores were added to the analysis, the effect of self-esteem changed, such that selfesteem now made a significant independent contribution to aggressive humor. 
Table 3 Summary of multiple regression analyses predicting affiliative humor style from self-esteem and interpersonal competence

\begin{tabular}{|c|c|c|c|c|c|c|c|c|c|}
\hline \multirow[t]{2}{*}{ Variable } & \multicolumn{3}{|c|}{ Model I } & \multicolumn{3}{|c|}{ Model 2} & \multicolumn{3}{|c|}{ Model 3} \\
\hline & $R^{2}$ & Beta & $P$ & $R^{2}$ & Beta & $P$ & $\overline{R^{2}}$ & Beta & $P$ \\
\hline & 0.04 & & & 0.15 & & & 0.20 & & \\
\hline Gender & & -0.08 & 0.257 & & -0.08 & 0.686 & & -0.07 & 0.290 \\
\hline Age & & -0.17 & 0.016 & & -0.23 & 0.001 & & -0.20 & 0.003 \\
\hline Self-esteem & & & & & 0.35 & 0.000 & & 0.25 & 0.001 \\
\hline Interpersonal competence & & & & & & & & 0.24 & 0.001 \\
\hline
\end{tabular}

In these analyses (Tables 3-6), self-esteem was related to all humor styles. Given that competence may in turn affect self-esteem, additional analyses were performed for mediation by interpersonal competence where it was also significantly related to humor style. The result was nonsignificant, indicating that interpersonal competence did not mediate the effects of self-esteem on humor. For the self-directed humor styles, high self-esteem predicted greater use of selfenhancing humor whereas low self-esteem predicted greater use of self-defeating humor. Interpersonal competence was not related to the self-directed humor styles. Both variables, ie, self-esteem and interpersonal competence, were related to the other-directed humor styles, whereby high self-esteem and high interpersonal competence each predicted higher affiliative humor scores and high self-esteem and low interpersonal competence predicted higher aggressive humor scores. Table 7 presents a summary of these outcomes. The direction of the self-esteem outcome for aggressive humor was not expected from the literature on humor styles, and possible reasons for this result are discussed below.

Given interpersonal competence contributed uniquely to the other-directed humor styles after controlling for selfesteem, the next step was to examine which of the competence subscales might contribute most to the relationship of competence and humor. Accordingly, a second set of hierarchical multiple regression analyses used the subscales of the ICQ (rather than the total) as predictors for the aggressive and affiliative humor styles, again controlling for gender and age. Initiation competence positively predicted greater use of affiliative humor styles (beta $0.39, P<0.001$ ) whereas both initiation competence (beta $0.25, P<0.005$ ) positively and conflict management competence (beta $-0.30, P<0.001$ ) negatively predicted greater use of aggressive humor styles. There was no relationship between self-esteem and aggressive humor in this second regression analysis.

\section{Discussion}

The relationships between humor styles, interpersonal competence, and self-esteem, as reported above, show a mixture of patterns. Self-esteem predicted all styles of humor, at least in the first set of regressions, with the only negative relationship found for self-defeating humor. Thus, those high on self-esteem scored higher on affiliative, aggressive, and self-enhancing humor styles, but lower on self-defeating humor styles. Interpersonal competence predicted the use of other-directed but not self-directed humor styles. Thus, high self-esteem and high interpersonal competence independently predicted greater affiliative humor use, whereas high self-esteem and low interpersonal competence independently predicted more use of aggressive humor.

These results initially suggested that when self-esteem is high, interpersonal competence scores are necessary to predict the specific type of other-directed humor. However, when the interpersonal competence variable was broken down into its subscales, any relationship between self-esteem and aggressive humor disappeared and a relationship with the initiation competence variable of the ICQ emerged. The Rosenberg Self-Esteem Inventory items (eg, being able to "do things well") leave room for interpretation. Our results

Table 4 Summary of multiple regression analyses predicting self-enhancing humor style from self-esteem and interpersonal competence

\begin{tabular}{|c|c|c|c|c|c|c|c|c|c|}
\hline \multirow[t]{2}{*}{ Variable } & \multicolumn{3}{|c|}{ Model I } & \multicolumn{3}{|c|}{ Model 2} & \multicolumn{3}{|c|}{ Model 3} \\
\hline & $\overline{R^{2}}$ & Beta & $P$ & $\overline{R^{2}}$ & Beta & $P$ & $\overline{R^{2}}$ & Beta & $P$ \\
\hline & 0.06 & & & 0.13 & & & 0.13 & & \\
\hline Gender & & -0.03 & 0.682 & & 0.03 & 0.730 & & 0.03 & 0.679 \\
\hline Age & & -0.11 & 0.125 & & 0.05 & 0.455 & & 0.05 & 0.493 \\
\hline Self-esteem & & & & & 0.35 & 0.001 & & 0.36 & 0.001 \\
\hline Interpersonal competence & & & & & & & & -0.09 & 0.702 \\
\hline
\end{tabular}


Table 5 Summary of multiple regression analyses predicting aggressive humor style from self-esteem and interpersonal competence

\begin{tabular}{|c|c|c|c|c|c|c|c|c|c|}
\hline \multirow[t]{2}{*}{ Variable } & \multicolumn{3}{|c|}{ Model I } & \multicolumn{3}{|c|}{ Model 2} & \multicolumn{3}{|c|}{ Model 3} \\
\hline & $R^{2}$ & Beta & $P$ & $R^{2}$ & Beta & $P$ & $R^{2}$ & Beta & $P$ \\
\hline & 0.12 & & & 0.12 & & & 0.19 & & \\
\hline Gender & & -0.26 & 0.001 & & -0.26 & 0.001 & & -0.20 & 0.003 \\
\hline Age & & -0.19 & 0.004 & & -0.20 & 0.004 & & -0.24 & 0.001 \\
\hline Self-esteem & & & & & 0.05 & 0.511 & & 0.17 & 0.022 \\
\hline Interpersonal competence & & & & & & & & -0.29 & 0.001 \\
\hline
\end{tabular}

suggest that users of aggressive humor may have interpreted some self-esteem items as social competence, and when a more direct measure was entered into the analysis (ie, the initiation subscale of the ICQ), the effect of self-esteem no longer contributed any independent information over and above the ability to initiate interactions. When this latter result is considered together with the low conflict management scores, our data suggest that users of aggressive humor feel confident about initiating humorous interactions, but these interactions are not used to manage interpersonal conflict well and may even increase it.

Being good at initiating interactions is normally considered a positive characteristic associated with good relationships. ${ }^{35}$ Consequently, Sahl et al reported surprise when they found initiating competence was predictive of higher levels of daily stress. ${ }^{40}$ They suggested that people with good initiation skills might initiate negative interactions if they were in a bad mood, which then leads to more interpersonal problems. We add as a specific example that such individuals may also be more likely to use aggressive humor in their interactions, which increases the likelihood of interpersonal problems and further contributes to what could seem to be a paradoxical relationship between initiation skills and stress. This speculation is supported by reports of poor quality relationships in those using aggressive humor. ${ }^{41}$ Divorced males have been rated as high in aggressive humor by themselves and former partners (compared with still married partners) and this use has been related to ongoing unsatisfactory interactions with ex-partners. ${ }^{42}$
Self-defeating humor and aggressive humor are usually positively correlated with each other, ${ }^{36}$ suggesting that the two negative humor styles may both be regarded as aggressive, but one uses inward and the other outward aggression. Given that humor styles differentially predict well-being, it is important to determine who uses styles that are aggressive to themselves or to others. That is, evaluation in this context can be less about tastes in humor and more on uses of humor.

Many people may enjoy aggressive humor (for example, aggressive cartoons or films) but do not use it on others. Aggressive humor styles such as sarcasm are used in certain therapeutic applications ${ }^{43}$ but these, it may be argued, are ironic uses of humor that are not truly aggressive when body language and voice are taken into account. Knowing how the "other" will respond is important to use of humor, whether in business, in the clinic, or in other personal interactions, and moreso when aggressive or self-defeating humor is used.

Self-defeating humor and low self-esteem predict low scores on measures of well-being. There is some debate in Australian humor research networks that self-defeating humor in the Australian context contains a large degree of ironic humor which is not intrinsically self-defeating or truly self-deprecating. ${ }^{44-46}$

Therefore, following this argument, we might have expected that high use of self-defeating humor would not be associated with low self-esteem in our Australian sample. However, self-defeating humor was associated with low self-esteem in this group, which suggests the HSQ measures something that is not the same as self-deprecation in

Table 6 Summary of multiple regression analyses predicting self-defeating humor style from self-esteem and interpersonal competence

\begin{tabular}{|c|c|c|c|c|c|c|c|c|c|}
\hline \multirow[t]{2}{*}{ Variable } & \multicolumn{3}{|c|}{ Model I } & \multicolumn{3}{|c|}{ Model 2} & \multicolumn{3}{|c|}{ Model 3} \\
\hline & $\overline{R^{2}}$ & Beta & $P$ & $\overline{R^{2}}$ & Beta & $P$ & $\overline{R^{2}}$ & Beta & $P$ \\
\hline & 0.06 & & & 0.13 & & & 0.13 & & \\
\hline Gender & & 0.01 & 0.848 & & -0.03 & 0.687 & & -0.02 & 0.785 \\
\hline Age & & -0.25 & 0.001 & & -0.21 & 0.003 & & -0.21 & 0.003 \\
\hline Self-esteem & & & & & -0.27 & 0.001 & & -0.25 & 0.001 \\
\hline Interpersonal competence & & & & & & & & -0.05 & 0.533 \\
\hline
\end{tabular}


Table 7 Summary of direction of relationships for personality characteristics and humor style

\begin{tabular}{lll}
\hline Humor style & $\begin{array}{l}\text { Interpersonal } \\
\text { competence }\end{array}$ & Self-esteem \\
\hline $\begin{array}{l}\text { Self-directed humor } \\
\text { Self-enhancing }\end{array}$ & Nonsignificant & Positive* \\
$\begin{array}{l}\text { Self-defeating } \\
\text { Other-directed humor } \\
\text { Affiliative }\end{array}$ & Nonsignificant & Negative* \\
Aggressive & Positive* & Positive* \\
\hline
\end{tabular}

the ironic sense. It is possible that this type of humor style is at times both ironic and self-defeating. As Averbeck and Hample ${ }^{47}$ have claimed, "despite appearing gentler than sarcasm, ironic messages still contain an attack". Self-defeating humor has also been associated with "supportive" humor, meaning it is used to put others at ease, although Martin et al would see this as a form of affiliative humor. ${ }^{23}$ Although some of the items on self-defeating humor on the HSQ suggest a social awareness of others, selfdefeating humor was not associated with any interpersonal competence scores, such as emotional support, in our study. In short, self-defeating humor showed results similar to those from a wide international set of studies, indicating that it is not a masked or ironic positive style. Against this, our results for aggressive humor using the HSQ were relatively novel.

This study examined a limited number of variables, and it is likely that factors other than interpersonal competence and self-esteem contribute to humor style or reflect it. We considered gender and age, with results replicating those in the literature, but other demographic variables were not included. It is likely that factors such as education level influence the use of humor style and potentially limit the generalizability of our results.

While not necessarily a limitation, it is also important to bear in mind that we have reported on predictors of humor use within individuals, but we are aware that people also respond to other individuals according to their humor style. The causal loop with such variables is complex. Kuiper and Leite $^{48}$ demonstrated that the humor styles a person used resulted in a different set of judgments about that person on scales such as introversion and neuroticism and on individual characteristics such as friendly, considerate, mean, or complaining. Clearly, many variables can be relevant to the use of and response to humor.

\section{Conclusion}

In this study, we have shown that interpersonal competence statistically predicted humor style over and above the contributions of age, gender, and self-esteem. The nature of the predictions depended on whether humor was positive or negative, and whether it was self-directed or other-directed. A future step will be to examine whether the judgments and reactions of other individuals to these uses of humor in turn influence the styles that people adopt. Such research is important so that we do not lose sight of the many ways we can use and respond to the complex set of phenomena we simply label "humor".

\section{Disclosure}

The authors report no conflicts of interest in this work.

\section{References}

1. Kuiper NA, Grimshaw M, Leite C, Kirsh G. Humor is not always the best medicine: specific components of sense of humor and psychological well-being. Humor. 2004;17(1-2):135-168.

2. Abel MH. Humor, stress, and coping strategies. Humor. 2002;15(4): 365-382.

3. Kuiper NA, Martin R, Dance KA. Sense of humour and enhanced quality of life. Pers Individ Dif. 1992;13(12):1273-1283.

4. Nezlek JB, Derks P. Use of humor as a coping mechanism, psychological adjustment, and social interaction. Humor. 2001;14(4): 395-413.

5. Freeman GP, Ventis WL. Does humor benefit health in retirement? Exploring humor as a moderator. J Psychol. 2010;6(3):122-148.

6. Porterfield AL. Does sense of humor moderate the impact of life stress on psychological and physical well-being? J Res Pers. 1987;21(3): 306-317.

7. Lefcourt HM, editor. Humor: The Psychology of Living Buoyantly. New York, NY: Kluwer Academic; 2001.

8. Herzog TR, Strevey SJ. Contact with nature, sense of humor, and psychological well-being. Environ Behav. 2008;40(6):747-776.

9. Kuiper NA, McKenzie SD, Belanger KA. Cognitive appraisals and individual differences in sense of humor: motivational and affective implications. Pers Individ Dif. 1995;19(3):359-372.

10. Veselka L, Schermer JA, Martin RA, Vernon PA. Laughter and resiliency: a behavioral genetic study of humor styles and mental toughness. Twin Res Hum Genet. 2010;13(5):442-449.

11. Ziv A. The social function of humor in interpersonal relationships. Society. 2010;47:11-18.

12. Kirsh GA, Kuiper NA. Positive and negative aspects of sense of humor: associations with the constructs of individualism and relatedness. Humor. 2003;16(1):33-62.

13. Moran CC, Thomas P, Milner-Davis J. Laughter, asthma and stress. Humor Health J. 2008;17(1):1-9.

14. Freud, S. Jokes and Their Relation to the Unconscious [trans J Strachey, 1976]. London: Penguin; 1905.

15. Hobbes T. The Elements of Law Natural and Politic. 1640. Available from: http://socserv2.socsci.mcmaster.ca/ econ/ugcm/3113/hobbes/ elelaw [cited March 7, 2011]. Accessed September 19, 2012.

16. Martin RA. Sense of humor and physical health: theoretical issues, recent findings, and future directions. Humor. 2004;17(1/2):1-20.

17. Moran CC. Humor and its link to meaning and spirituality in war. In: MacKinlay E, editor. Ageing Disability and Spirituality. London, UK: Jessica Kingsley; 2008.

18. Moran C, Figley C. Humor as a moderator of compassion fatigue. In: Figley C, editor. Treating Compassion Fatigue. New York, NY: Routledge; 2002.

19. Edwards KR, Martin RA. Humor creation ability and mental health: are funny people more psychologically healthy? Eur J Psychol. 2010;6(3): 196-212. 
20. Barelds DPH, Barelds-Dijkstra P. Humor in intimate relationships: ties among sense of humor, similarity in humor and relationship quality. Humor. 2010;23(4):447-465.

21. Moran CC, Hughes LP. Coping with stress: social work students and humour. Soc Work Educ. 2006;25(5):501-517.

22. Keyton J, Beck SJ. Examining laughter functionality in jury deliberations. Small Group Res. 2010;41(4):386-407.

23. Martin RA, Puhlik-Doris P, Larsen G, Gray J, Weir K. Individual differences in uses of humor and their relation to psychological well-being: development of the Humor Styles Questionnaire. J Res Pers. 2003;37(1):48-75.

24. Campbell L, Martin RA, Ward JR. An observational study of humor use while resolving conflict in dating couples. Pers Relatsh. 2008;15(1): 41-55.

25. Kuiper NA, Borowicz-Sibenik M. A good sense of humor doesn't always help: agency and communion as moderators of psychological well-being. Pers Individ Dif. 2005;38(2):365-377.

26. Mauriello M, McConatha JT. Relations of humor with perception of stress. Psychol Rep. 2007;101(3F):1057-1066.

27. Yip JA, Martin RA. Sense of humor, emotional intelligence, and social competence. J Res Pers. 2006;40(6):12021-12208.

28. Dozois DJA, Martin RA, Bieling PJ. Early maladaptive schemas and adaptive/maladaptive styles of humor. Cognit Ther Res. 2009;33(6): 585-596.

29. Fitts SD, Sebby RA, Zlokovich MS. Humor styles as mediators of the shyness-loneliness relationship. North Am J Psychol. 2009;11(2): 257-272.

30. Bell NJ, McGhee PE, Duffey NS. Interpersonal competence, social assertiveness and the development of humour. Br J Dev Psychol. 1986;4(1):51-55.

31. Graham EE, Papa MJ, Brooks GP. Functions of humor in conversation: conceptualization and measurement. West J Commun. 1992;56(2): 161-183.

32. Hampes WP. Humor and shyness: the relation between humor styles and shyness. Humor. 2006;19(2):179-187.

33. Stieger S, Formann AK, Burger C. Humor styles and their relationship to explicit and implicit self-esteem. Pers Individ Dif. 2011;50(5): 747-750.

34. Armistead L, Forehand R, Beach SRH, Brody GH. Predicting interpersonal competence in young adulthood: The roles of family, self, and peer systems during adolescence. J Child Fam Stud. 1995;4(4):445-460.
35. Buhrmester D, Furman W, Wittenberg MT, Reis HT. Five domains of interpersonal competence in peer relationships. J Pers Soc Psychol. 1988;55(6):991-1008.

36. Martin RA. The Psychology of Humor: An Integrative Approach. Burlington, MA: Elsevier Academic Press; 2007.

37. Rosenberg M. Conceiving the Self. Malabar, FL: Robert E Krieger Publishing Company; 1986.

38. Robins RW, Hendin HM, Trzesniewski KH. Measuring global selfesteem: construct validation of a single-item measure and the Rosenberg Self-Esteem Scale. Pers Soc Psychol Bull. 2001;27(2):151-161.

39. Tabachnick BG, Fidell LS, Osterlind SJ. Using Multivariate Statistics. Boston, MA: Pearson, Allyn and Bacon; 2001.

40. Sahl JC, Cohen LH, Dasch KB. Hostility, interpersonal competence, and daily dependent stress: a daily model of stress generation. Cognit Ther Res. 2009;33(2):199-210.

41. Zeigler-Hill V, Besser A. Humor style mediates the association between pathological narcissism and self-esteem. Person Individ Dif. 2011;50(8):1196-1201.

42. Saroglou V, Lacour C, Demeure ME. Bad humor, bad marriage: Humor styles in divorced and married couples. J Psychol. 2010;6(3):94-121.

43. Ruvelson L. The empathic use of sarcasm: Humor in psychotherapy from a self psychological perspective. Clin Soc Work J. 1988;16(3): 297-305.

44. Milner Davis J. "Aussie" humour and laughter: joking as an acculturating ritual. In: Kirkpatrick P, de Groen F, editors. Serious Frolic: Essays on Australian Humour. St Lucia, Queensland: University of Queensland Press; 2009:31-47.

45. Moran CC. Regional identity and humor. In: Blacklow N, Whitford T, editors. Where the Crows Fly Backwards: Notions of Rural Identity. Brisbane, Australia: PostPress; 2010.

46. Rawling M, Findlay B. Humor about the self: enhancing/defeating or deprecating? 17th Australasian Humor Studies Network Colloquium on “Time, Place and Humor". September 30-October 2, 2010, University of Sydney, Australia.

47. Averbeck JM, Hample D. Ironic message production: how and why we produce ironic messages. Communication Monographs. 2008;75(4): 396-410.

48. Kuiper NA, Leite C. Personality impressions associated with four distinct humor styles. Scand J Psychol. 2010;51(2):115-122.
Psychology Research and Behavior Management

\section{Publish your work in this journal}

Psychology Research and Behavior Management is an international, peerreviewed, open access journal focusing on the science of psychology and its application in behavior management to develop improved outcomes in the clinical, educational, sports and business arenas. Specific topics covered include: Neuroscience, memory \& decision making; Behavior

\section{Dovepress}

modification \& management; Clinical applications; Business \& sports performance management; Social and developmental studies; Animal studies. The manuscript management system is completely online and includes a quick and fair peer-review system. Visit http://www.dovepress. $\mathrm{com} /$ testimonials.php to read real quotes from published authors. 